\title{
Heart Rate Variability in Children with Bronchiolitis Obliterans
}

Rodrigo Torres-Castro ${ }^{1,2 *}$, Francisco Quinteros ${ }^{1}$, Cynthia Valdés ${ }^{1}$, Claudio Santín ${ }^{1}$, Roberto Vera-Uribe ${ }^{1}$, Matías Otto-Yáñez ${ }^{2,3}$, Javiera Rosales-Fuentes ${ }^{1}$ and Marcelo Cano-Cappellacci ${ }^{1}$

${ }^{1}$ Department of Physical Therapy, Faculty of Medicine, University of Chile, Santiago, Chile

${ }^{2}$ Center for Integrated Studies in Neurorehabilitation, Clínica Los Coihues, Santiago, Chile

${ }^{3}$ School of Kinesiology, Autonomous University of Chile, Santiago, Chile

\begin{abstract}
Post-infectious bronchiolitis obliterans (PIBO) is a respiratory disease characterised by obstruction of the small airways. This obstruction limits the exercise capacity and reduces the quality of life of affected children. Two children with PIBO who were 10 and 14 years of age and both oxygen-dependent are presented. Both children underwent heart rate variability (HRV) measurements, revealing an increase in the LFnu and the LF/HF ratio and demonstrating a predominant effect on the sympathetic system. The functional capacity was assessed by a six-minute walking test (6MWT), and the distance travelled was lower than the reference values. Spirometry revealed advanced obstructive ventilatory limitation in both cases. The HRV measurements are consistent with the decrease in physical fitness in these children and indicate the need for further studies on HRV in this pathology.
\end{abstract}

Keywords: Heart rate variability; Post-infectious bronchiolitis obliterans; Six-minute walking test; Exercise tolerance

\section{Description}

\section{Case 1}

The first case is a 14-year-old girl, F.O., diagnosed with postinfectious bronchiolitis obliterans (PIBO) due to adenovirus (ADV) infection during the first year of life. At the time of evaluation, the patient had a height of $1.32 \mathrm{~m}$ and a weight of $35 \mathrm{~kg}$. She required 0.5 $\mathrm{L}$ of $\mathrm{O}_{2}$ by nose and the use of nocturnal non-invasive mechanical ventilation (NIV). F.O. presented with the following parameters: forced vital capacity (FVC), $1.25 \mathrm{~L}$ (60\% of predicted); forced exhaled volume in one second $\left(\mathrm{FEV}_{1}\right), 0.8 \mathrm{~L}$ ( $44 \%$ of predicted); $\mathrm{FEV}_{1} / \mathrm{FVC}, 64 \%$ relative to the reference; six-minute walking test (6MWT) distance, $514 \mathrm{~m}(78 \%$ relative to the reference value).

\section{Case 2}

The second case is a 10-year-old boy, M.L., diagnosed with PIBO due to infection with ADV in the first year of life. At the time of the evaluation, the patient had a height of $1.40 \mathrm{~m}$ and a weight of $41 \mathrm{~kg}$. The patient used $0.5 \mathrm{~L} \mathrm{O}_{2}$ by nose and nocturnal NIV and presented with the following parameters: FVC, $1.45 \mathrm{~L}$ ( $60 \%$ of predicted); $\mathrm{FEV}_{1}, 0.73$ $\mathrm{L}$ ( $35 \%$ of predicted); $\mathrm{FEV}_{1} / \mathrm{FVC}, 64 \%$ relative to the reference value; $6 \mathrm{MWT}$ distance, $356 \mathrm{~m}$, (53\% compared with the reference value).

\section{Investigations}

Evaluation of the heart rate variability (HRV) was performed with a portable Polar RS800 heart rate monitor (Polar Electro OY, Kempele, Finland) with the patient in a supine position for 15 minutes. During the recording, both patients were resting in a quiet environment. The first 5 minutes were used to normalise the parameters, and the next 10 minutes were considered for the analysis. The data were analysed using the HRV Analysis software 1.1 (Biomedical Signal Analysis Group, Department of Applied Physics, University of Kuopio, Finland). The frequency domains were analysed by applying Fast Fourier Transform in a single window after subtracting the linear tendency using automatic filters on previously selected R-R intervals. The domains were studied using low- (LF: 0.04 to $0.15 \mathrm{~Hz}$ ) and high- (HF: 0.15 to $0.4 \mathrm{~Hz}$ ) frequency ranges and are presented as the spectral density $\left(\mathrm{ms}^{2}\right)$, power $(\%)$ and normalised units (nu). The low-frequency/high-frequency (LF/HF) ratio was also calculated.
An evaluation of lung function was performed with a Medgraphics Ultima CPX (Medical Graphics Corp, St Paul, MN, USA) spirometer, and the absolute and percentage values have been determined for a Chilean reference sample [1]. The $6 \mathrm{MWT}$ was performed to assess the functional capacity and obtain the distance travelled, and the result is presented relative to the predicted reference values [2].

The HRV values are shown in Table 1.

\section{Discussion}

PIBO is a lung disease characterised by airflow obstruction in the small airways. This condition arises primarily as a result of inflammation and fibrosis in the affected area caused by viral infection [3]. The incidence is higher in developing countries, and ADV is a common pathogen in Chile [3]. Children with PIBO have difficulty

\begin{tabular}{|c|c|c|c|}
\hline Index & $\begin{array}{c}\text { Case 1 } \\
\text { (F.0.) }\end{array}$ & $\begin{array}{c}\text { Case 2 } \\
\text { (M.L.) }\end{array}$ & $\begin{array}{c}\text { Healthy subjects }(\mathbf{n}=12 \text { by } \\
\text { Florêncio et al.) [4] }\end{array}$ \\
\hline Mean R-R (s) & 0.6 & 0.9 & Not reported \\
\hline Mean HR (beat/min) & 89.3 & 68.7 & $94 \pm 7.7$ \\
\hline RMSSD (ms) & 34.4 & 72.5 & Not reported \\
\hline LFnu & 70.2 & 44.1 & $32.8 \pm 7.9$ \\
\hline HFnu & 29.8 & 55.9 & $68.3 \pm 8.7$ \\
\hline LF/HF (\%) & 2.36 & 0.8 & $0.49 \pm 0.18$ \\
\hline
\end{tabular}

R-R: Interval; HR: Heart rate; RMSSD: Square root of the mean of squares for differences between successive R-R; LFnu: Low frequency in normalised units; HFnu: High frequency in normalised units; LF/HF: Low-frequency/High-frequency ratio.

Table 1: Heart rate variability values.

*Corresponding author: Rodrigo Torres-Castro, School of Kinesiology, University of Chile Independencia 1027, Santiago, Chile, Tel: (562)29786513; E-mail: klgorodrigotorres@gmail.com

Received July 25, 2016; Accepted September 30, 2016; Published September 30, 2016

Citation: Torres-Castro R, Quinteros F, Valdés C, Santín C, Vera-Uribe R, et al. (2016) Heart Rate Variability in Children with Bronchiolitis Obliterans. J Clin Respir Dis Care 2: 119. doi: 10.4172/2472-1247.1000119

Copyright: (c) 2016 Torres-Castro R, et al. This is an open-access article distributed under the terms of the Creative Commons Attribution License, which permits unrestricted use, distribution, and reproduction in any medium, provided the original author and source are credited. 
Citation: Torres-Castro R, Quinteros F, Valdés C, Santín C, Vera-Uribe R, et al. (2016) Heart Rate Variability in Children with Bronchiolitis Obliterans. J Clin Respir Dis Care 2: 119. doi: 10.4172/2472-1247.1000119

during physical activity and exhibit a worsening of the respiratory symptoms during exercise, which could affect their normal growth and psychomotor development [3]. The 6MWT is a submaximal test used to assess exercise tolerance and correlates well with the activities of daily living (ADL) [4]. The 6MWT has been validated in children and adults. Reference values are available for healthy Chilean children, and this test has been used in national studies of children with PIBO [3].

Another diagnostic method associated with exercise tolerance is the HRV [5]. Determination of the HRV is a non-invasive method to estimate the balance of the autonomic nervous system (ANS) and its influence on the cardiovascular response during exercise. Analysis of the HRV can be performed using ECG data to determine the duration of consecutive R-R intervals. Alternatively, it is possible to obtain the $\mathrm{R}-\mathrm{R}$ interval using a heart rate monitor [5].

For both of the cases described here, the HRV was altered compared with the reference values. The values of the low-frequency normalised units (LFnu) were high (70 and 44), demonstrating a high level of sympathetic activity. These data are consistent with the results described by Florêncio et al. [4], who evaluated children with cystic fibrosis (CF); in their study, the average LFnu of the CF patients was 53.2, whereas that of the control group was 32.8. Although group comparisons are not possible in this case study, the LFnu values obtained were greater than those of the control group reported by Florêncio et al. [4] (32.8) and the unpublished values obtained in our pilot study ( 6 healthy subjects with an average LFnu of 37). Both studies were conducted with children of similar ages. The high sympathetic tone in the cases described here may also be related to the higher value of the LF/HF ratio (2.4 and 0.8 for case 1 and case 2, respectively). This ratio was 1.25 in the CF group and 0.49 in the control group in the study by Florêncio, and we obtained an LF/HF ratio of 0.6 in our pilot study (unpublished). In the case 2, we think that the significant difference of LF/HF respect to the case 1 and data reported by Florêncio et al. [6], is due to the advanced state of the disease characterized by lower walked distance in 6MWT and lower $\mathrm{FEV}_{1}$. This predominance of sympathetic activity may contribute to the pathophysiology of cardiovascular disease and could result from changes in the breathing pattern, high levels of catecholamines or the permanently increased level of work associated with breathing [6].

In both of our cases, Spirometry revealed a pattern typical of obstructive pathology, highlighting the advanced obstructive airflow limitation ( $\mathrm{FEV}_{1}$ of $44 \%$ and $35 \%$ ) characterised by difficulty in expelling air from the lungs. This is an important factor that limits the performance of physical exercise, mainly due to the difficulty of meeting the requirements needed to carry oxygen to the tissues, including skeletal muscle. Furthermore, airflow obstruction may generate a dynamic hyperinflation, as previously observed in studies of patients with PIBO [3].

Both cases in this study were demonstrated to have an exercise capacity, as demonstrated by the $6 \mathrm{MWT}$ ( $78 \%$ and $53 \%$ relative to the predicted values). This result is consistent with previous studies in Chile [7].

Importantly, the reference values for this test are based on height and weight. The patients described here were less than $1.40 \mathrm{~m}$ in height and weighed less than $41 \mathrm{~kg}$, and these values are lower than the values expected for a child undergoing normal physical development. In addition to the obstructive nature of the pathology, the difficulty of walking with an oxygen cylinder and the effects of chronic oxygen use contribute to the reduced exercise capacity in these patients.

This is the first report describing an assessment of the HRV in patients with PIBO. Our results indicate that there were changes in the parameters related to the cardiovascular and sympathetic response to exercise. Our findings also highlight the need to generate reference values for a population with similar characteristics. These reference values would improve the analysis of the data, they would contribute to future research on the effects of therapeutic interventions such as exercise, and they would allow for the development of noninvasive methods to assess cardiovascular risk.

\section{Learning Points}

Children with post-infectious bronchiolitis obliterans have diminished physical condition.

Heart rate variability is a good indicator of physical condition in patients with chronic respiratory diseases.

\section{References}

1. Knudson R, Lebowitz M, Holberg C, Burrows $B$ (1983) Changes in the Normal Maximal Expiratory Flow-Volumen Curve with Growth and Aging. Am Rev Respir Dis 27: 725-734.

2. Geiger R, Strasak A, Treml B, Gasser K, Kleinsasser A, et al. (2007) Six-Minute Walk Test in Children and Adolescents. J Pediatr 150: 395-399.

3. Fisher GB, Sarria EE, Mattiello R, Mocelin H, Castro-Rodriguez JA (2010) Post Infectious Bronchiolitis Obliterans in Children. Ped Respir Rev 11: 233-239

4. ATS Committee on Proficiency Standards for Clinical Pulmonary Function Laboratories (2012) ATS statement: guidelines for the six-minute walk test. Am J Respir Crit Care Med 166: 111-117.

5. Kleiger R, Miller J, Bigger J, Moss A (1987) Decreased heart rate variability and its association with increased mortality after acute myocardial infarction. Am J Cardiol 59: 256-262.

6. Florêncio R, Fregonezi G, Brilhante S, Borghi-Silva A, Dias F et al. (2013) Heart Rate Variability at rest and after the 6-minute walk test (6 MWT) in children with cystic fibrosis. Braz J Phys Ther 17: 419-426.

7. Zenteno D, Puppo H, González R, Pavón D, Vera R, et al. (2008) Test de marcha de seis minutos en niños con bronquiolitis obliterante postviral: Correlación con espirometría. Rev Chil Enferm Respir 24: 15-19. 